\title{
Sofosbuvir-Based Regimens for Chronic Hepatitis C in a Well-Insured U.S. Population: Patient Characteristics, Treatment Adherence, Effectiveness, and Health Care Costs, 2013-2015
}

\author{
Shaoman Yin, PhD, MSPH; Laurie Barker, MSPH; Jianglan Z. White, MD, MPH; and Ruth B. Jiles, PhD
}

\begin{abstract}
BACKGROUND: Chronic hepatitis $\mathrm{C}(\mathrm{CHC})$ is a leading cause of morbidity and mortality and has imposed a high health care burden in the United States. Direct-acting antiviral (DAA) regimens are well tolerated and highly effective for CHC therapy but were initially marketed at a high price. Studies of their real-world use with a nationwide population are limited.

OBJECTIVE: To examine patient characteristics, treatment adherence, effectiveness, and health care costs in a large U.S. population with commercial and Medicare supplemental insurance plans who received simeprevir (SIM), sofosbuvir (SOF), or ledipasvir/sofosbuvir (LED/SOF) during the years 2013-2015.

METHODS: Patients with at least 1 diagnosis code for $\mathrm{CHC}$ and at least 1 claim for SIM, SOF, or LED/SOF prescriptions were selected. The date of the first claim for SIM, SOF, or LED/SOF was defined as the index date. Analyses were stratified by 4 regimens: $S O F+S I M \pm$ ribavirin (RBV), $\mathrm{SOF}+$ peginterferon alpha-2a or $2 \mathrm{~b}(\mathrm{PEG})+\mathrm{RBV}, \mathrm{SOF}+\mathrm{RBV}$, and LED/ $\mathrm{SOF} \pm \mathrm{RBV}$. Adherence was defined by the proportion of days covered $(P D C) \geq 80 \%$. Sustained virologic response (SVR12) was defined as a hepatitis $\mathrm{C}$ virus (HCV) RNA load of $\leq 25 \mathrm{IU} / \mathrm{mL}$ measured at $\geq 12$ weeks following the end of the days supply of the last DAA refill. Health care costs such as DAA drug costs and medical costs (inpatient costs plus outpatient costs) were described.
\end{abstract}

RESULTS: Of 10,808 CHC patients, approximately two thirds were male, and mean age was 55 years. The proportion of patients with compensated cirrhosis among each regimen ranged from $7.4 \%$ in $\mathrm{LED} / \mathrm{SOF} \pm \mathrm{RBV}$ to $13.8 \%$ in $\mathrm{SOF}+\mathrm{SIM} \pm \mathrm{RBV}$, and the proportion of patients with decompensated cirrhosis ranged from $3.9 \%$ in $L E D / S O F \pm R B V$ to $10.7 \%$ in SOF $+\mathrm{SIM} \pm \mathrm{RBV}$. The majority of patients $(89.0 \%)$ used the newer regimen $\mathrm{LED} / \mathrm{SOF} \pm \mathrm{RBV}$ in 2015. Adherence rates were estimated at $80.5 \%, 81.5 \%, 85.7 \%$, and $91.4 \%$ for SOF + SIM \pm RBV $(n=1,761)$; SOF + PEG + RBV $(n=1,314)$; SOF + RBV $(n=1,994)$; and LED/SOF \pm RBV $(n=5,739)$, respectively. Regimen-specific adherence predictors included sex, age group, payer type, health plan, and treatment option with RBV. Being born during 1945-1965, liver disease severity, and Charlson Comorbidity Index levels did not predict adherence in any regimen. Overall SVR12 was $92.6 \%$ in 203 patients with available HCV RNA results: $100 \%(41 / 41)$ in SOF + SIM \pm RBV; $83.3 \%(25 / 30)$ in SOF + PEG + RBV; 90.6\% (29/32) in SOF + RBV; and 93\% (93/100) in LED/ $\mathrm{SOF} \pm \mathrm{RBV}$. While the drug costs for these DAA regimens were initially high, they had decreased $18.9 \%(P<0.001)$ during 2013-2015. Medical costs decreased $9.2 \%(P<0.001) 1$ year after the index dates.

CONCLUSIONS: These results indicate that DAA drug costs decreased steadily during $2013-2015$ and that $89 \%$ of patients on SOF-based DAA regimens took newer, lower-cost regimens with adherence rates above $80 \%$. Available data show that SVR12 rates were close to those obtained in clinical studies. Medical costs also significantly decreased 1 year after the index dates.

J Manag Care Spec Pharm. 2019;25(2):195-204

Copyright $\odot 2019$, Academy of Managed Care Pharmacy. All rights reserved.

\section{What is already known about this subject}

Chronic hepatitis $\mathrm{C}(\mathrm{CHC})$ is a major cause of morbidity and mortality and has resulted in significant health care expenditures in the United States.

The sofosbuvir (SOF)-based direct-acting antiviral (DAA) regimens have demonstrated high cure rates, good tolerability, and shorter treatment periods for CHC compared with older treatment options.

Studies of the SOF-based regimens have been conducted mainly in clinical trials, cohort registries, and among U.S. military veterans; however, the real-world use of these regimens in the larger population is less described.

\section{What this study adds}

This study assessed patient characteristics, treatment adherence, effectiveness, and health care costs of CHC treatment in a large U.S. population with commercial and Medicare supplemental insurance plans who were treated with SOF-based regimens during during the years 2013-2015.

The majority of patients on SOF-based DAA regimens took newer, lower cost regimens with high adherence, with SVR12 rates close to those obtained in clinical studies.

Drug costs for SOF-based regimens were initially high but decreased steadily during 2013-2015, along with medical costs, which also significantly decreased 1 year after the initiation of DAA treatment.

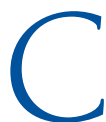
hronic hepatitis $\mathrm{C}(\mathrm{CHC})$ is a major cause of morbidity and mortality and has resulted in significant health care expenditures in the United States. ${ }^{1}$ Historically, $\mathrm{CHC}$ has been treated with a combination of peginterferon alpha-2a or $2 \mathrm{~b}$ (PEG) and ribavirin (RBV) for 24 or 28 weeks, with adverse effects and modest sustained virologic response (SVR) rates (40\%-50\%). ${ }^{2}$ In 2011, the U.S. Food and Drug Administration (FDA) approved 2 protease inhibitorsboceprevir and telaprevir - to treat CHC in combination with PEG and RBV. These regimens improved SVR rates up to $70 \%$ but with increased adverse events and discontinuations. ${ }^{3} \mathrm{~A}$ breakthrough in $\mathrm{CHC}$ therapy came with new direct-acting antiviral (DAA) regimens, including simeprevir (SIM, approved 
December 3, 2013), ${ }^{4}$ sofosbuvir (SOF, approved December 6, 2013), ${ }^{5}$ and ledipasvir/sofosbuvir (LED/SOF, approved October 10, 2014). ${ }^{6}$ Combinations of these medicines with or without RBV have demonstrated high SVR rates $(\geq 90 \%$ ), good tolerability, and shorter treatment period. ${ }^{7,8}$

Studies of the SOF-based regimens have been conducted mainly in clinical trials, ${ }^{9-14}$ cohort registries (e.g., TRIO and TARGET) ${ }^{15-18}$ and among U.S. military veterans. ${ }^{19-21}$ Patient characteristics and treatment management in routine medical practice and the wider $\mathrm{CHC}$ patient population could differ from that of tightly controlled clinical trials, cohort participations, and the veteran population. For example, treatment adherence in routine care is complex and influenced by many factors, including characteristics and preferences of patients and providers, payer policies, and other health system factors. Data on adherence to SOF-based regimens in larger populations are limited.

Understanding the cost of SOF-based regimens within the context of all health care costs of treating $\mathrm{CHC}$ remains important to patients, providers, payers, and other stakeholders. The wholesale acquisition cost (WAC) for SOF was approximately $\$ 84,000$ in 2017 for a 12-week treatment course, ${ }^{22}$ not accounting for additional costs, such as those from the drug supply chain, other regimen components, and pharmacy dispensing fees. The actual drug costs may be modified further by price negotiations between pharmacy benefit managers (PBMs), drug manufacturers, and payers. Actual DAA costs have been estimated by a few small-scale studies in local ambulatory care settings. ${ }^{23-26}$ The magnitude of these DAA costs for the nationwide population is not well known.

Since December 2013, the SOF-based regimens have been widely used among CHC patients who received treatment in the United States. Some aspects of this use are recorded in health care claims data, including Truven Health MarketScan Research Databases, which features a large database of claims from over 170 million patients since 1995. The goal of this study was to use the MarketScan databases to describe patient characteristics, treatment adherence, effectiveness, and health care costs among CHC-diagnosed patients who had claims for SOF-based regimens paid by commercial or Medicare supplemental insurance during 2013-2015.

\section{Methods}

\section{Data Sources}

This study used data from MarketScan Commercial Claims and Encounters (CCAE) and Medicare Supplemental databases from January 1, 2012, through December 31, 2015. The 2015 claims database contained claims initiated in 2015 but with processing dates through March 2016. These databases contain deidentified information about enrollment and medical and pharmacy claims for approximately 91 million persons, including active employees, early retirees, and their dependents. Claim records contain demographics (e.g., age, sex, and geographic region); health plan enrollment; and characteristics of health services utilization such as service date, International Classification of Diseases, Ninth Revision, Clinical Modification (ICD-9-CM) diagnosis, Current Procedural Terminology (CPT) codes, Healthcare Common Procedure Coding System (HCPCS) codes, payments, and drug prescriptions filled for each enrollee. Starting October 1, 2015, International Classification of Diseases, Tenth Revision, Clinical Modification (ICD-10-CM) has been used in the MarketScan databases. This study also used MarketScan lab databases (from January 1, 2012, through December 31, 2015), which are linked claimlaboratory databases for a subset of approximately 3 million enrollees included in the claim databases. This descriptive analysis used only deidentified health care claims data, which did not require institutional review board approval.

\section{Study Population}

Patients with at least 1 diagnosis code for CHC (ICD-9-CM codes 070.44, 070.54, 070.70, and 070.71; ICD-10-CM codes B18.2, B19.20, and B19.21) and at least 1 claim for SIM, SOF, or LED/SOF prescriptions were selected. The date of the first claim for SIM, SOF, or LED/SOF was defined as the treatment initiation date or the index date. Patients with any diagnosis for hepatitis B (ICD-9-CM codes 070.20, 070.21, 070.22, 070.23, 070.30, 070.31, 070.32, and 070.33; ICD-10-CM codes B16.0, B16.1, B16.2, B16.9, B18.0, B18.1, B19.10, and B19.11) were excluded. To be eligible for the analysis, patients were required to have (a) continuous enrollment in a health plan at least 6 months before and after the index date; (b) paid claims for $\mathrm{SOF}+\mathrm{SIM} \pm \mathrm{RBV}, \mathrm{SOF}+\mathrm{PEG}+\mathrm{RBV}, \mathrm{SOF}+\mathrm{RBV}$, or $\mathrm{LED} /$ $\mathrm{SOF} \pm \mathrm{RBV}$ regimens; and (c) at least 1 claim with DAA drug supply information following the index date (Appendix A, available in online article).

The 6-month period after the index date was selected because the longest treatment regimen in this study was 24 weeks or 5.6 months. The earliest possible index date for this analysis was November 2013, when SIM was approved by the FDA, and the latest possible index date was in early July 2015, to allow a minimum of 6 months continuous enrollment after the index date.

\section{Patient Characteristics}

Patient demographic characteristics and clinical conditions were summarized using available claims data 1 year before the index date. Demographic characteristics included age, sex, geographic region, payer type, and health insurance plan. Clinical conditions included Charlson Comorbidity Index (CCI) score $\mathrm{s}^{27}$ and comorbidities of interest such as compensated cirrhosis, decompensated cirrhosis, human immunodeficiency virus (HIV) infection, liver cancer, and liver transplant. History of 
Sofosbuvir-Based Regimens for Chronic Hepatitis C in a Well-Insured U.S. Population:

Patient Characteristics, Treatment Adherence, Effectiveness, and Health Care Costs, 2013-2015

TABLE 1 Demographic Characteristics of Patients Who Received SOF-Based Regimens for CHC Therapy in a U.S. Population with Commercial and Medicare Supplemental Insurance Plans, a 2013-2015

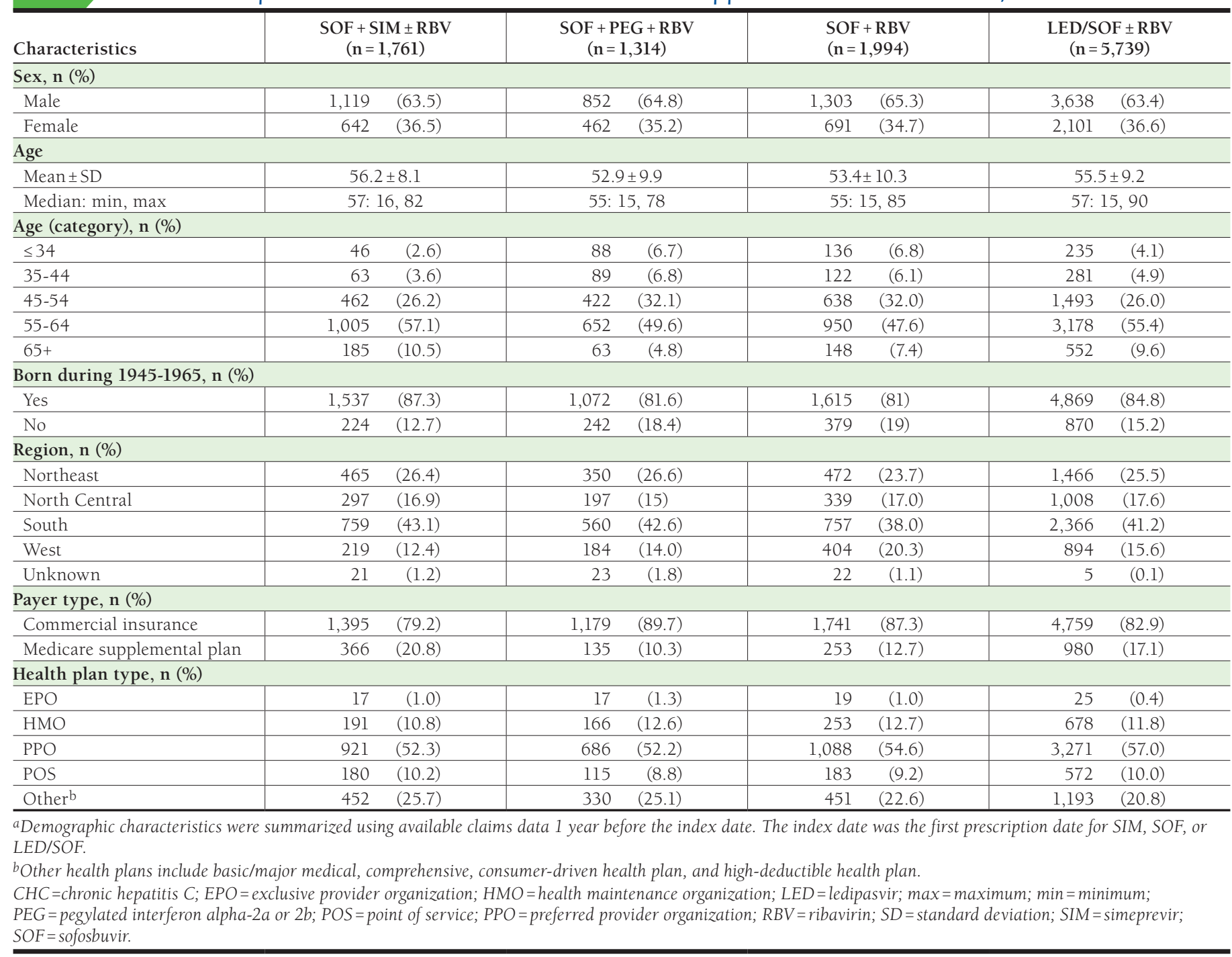

alcohol dependence and abuse and injection and noninjection drug use were also included. All related ICD-9-CM, ICD10-CM, CPT, and other codes are provided in Appendix B (available in online article).

\section{Treatment Adherence}

Depending on patient clinical characteristics and hepatitis C virus (HCV) genotypes, the FDA has recommended various treatment courses, such as 12 or 24 weeks for the SOF $+\mathrm{SIM} \pm \mathrm{RBV}$, $\mathrm{SOF}+\mathrm{PEG}+\mathrm{RBV}, \mathrm{SOF}+\mathrm{RBV}$ regimens and 8, 12, or 24 weeks for the $\mathrm{LED} / \mathrm{SOF} \pm \mathrm{RBV}$ regimen. Due to lack of genotype information and possibly missing data for cirrhosis and previous $\mathrm{CHC}$ treatment, the intended treatment duration could not be distinguished in this study. To estimate adherence rate, proportion of days covered (PDC) was used based on available literature. ${ }^{28-30}$ PDC was calculated as the number of days covered by the DAA drugs divided by the total treatment duration days. For the $\mathrm{SOF}+\mathrm{SIM} \pm \mathrm{RBV}, \mathrm{SOF}+\mathrm{PEG}+\mathrm{RBV}$, and $\mathrm{SOF}+\mathrm{RBV}$ regimens, we defined the total treatment duration as 12 weeks (84 days), if the observation period (duration between the index date and last refill date plus days of last drug supply) was within 14 weeks. Otherwise, we assumed the regimens were intended for 24 weeks (168 days) of treatment. For the $\mathrm{LED} / \mathrm{SOF} \pm \mathrm{RBV}$ regimen, we defined the total treatment duration as 8 weeks (56 days, observation period $\leq 10$ weeks); 12 weeks (84 days, observation period > 10 weeks and observation period $\leq 14$ weeks); or 24 weeks (168 days, observation period > 14 weeks). Given that higher values of PDC imply 
Sofosbuvir-Based Regimens for Chronic Hepatitis C in a Well-Insured U.S. Population:

Patient Characteristics, Treatment Adherence, Effectiveness, and Health Care Costs, 2013-2015

TABLE 2 Clinical Characteristics of Patients Who Received SOF-Based Regimens for CHC Therapy in a U.S. Population with Commercial and Medicare Supplemental Insurance Plans, ${ }^{a}$ 2013-2015

\begin{tabular}{|c|c|c|c|c|c|c|c|c|}
\hline Characteristics & \multicolumn{2}{|c|}{$\begin{array}{c}\mathrm{SOF}+\mathrm{SIM} \pm \mathrm{RBV} \\
(\mathrm{n}=1,761)\end{array}$} & \multicolumn{2}{|c|}{$\begin{array}{c}\text { SOF + PEG + RBV } \\
(\mathrm{n}=1,314)\end{array}$} & \multicolumn{2}{|c|}{$\begin{array}{l}\text { SOF + RBV } \\
(\mathrm{n}=1,994)\end{array}$} & \multicolumn{2}{|c|}{$\begin{array}{c}\mathrm{LED} / \mathrm{SOF} \pm \mathrm{RBV} \\
(\mathbf{n}=5,739)\end{array}$} \\
\hline \multicolumn{9}{|c|}{ Treatment option with RBV, n (\%) } \\
\hline No & 1,506 & $(85.5)$ & \multicolumn{2}{|c|}{ NA } & \multicolumn{2}{|c|}{ NA } & 5,470 & $(95.3)$ \\
\hline Yes & 255 & $(14.5)$ & & & & & 269 & $(4.7)$ \\
\hline \multicolumn{9}{|l|}{ Liver disease severity, $\mathbf{n}(\%)$} \\
\hline Noncirrhotic disease & 1,330 & $(75.5)$ & 1,086 & $(82.6)$ & 1,612 & $(80.8)$ & 5,094 & $(88.8)$ \\
\hline Compensated cirrhosis & 243 & (13.8) & 173 & $(13.2)$ & 204 & $(10.2)$ & 422 & $(7.4)$ \\
\hline Decompensated cirrhosis & 188 & $(10.7)$ & 55 & $(4.2)$ & 178 & $(8.9)$ & 223 & $(3.9)$ \\
\hline \multicolumn{9}{|l|}{ Liver cancer, n (\%) } \\
\hline No & 1,709 & $(97.0)$ & 1,305 & $(99.3)$ & 1,944 & $(97.5)$ & 5,674 & $(98.9)$ \\
\hline Yes & 52 & $(3.0)$ & 9 & $(0.7)$ & 50 & $(2.5)$ & 65 & $(1.1)$ \\
\hline \multicolumn{9}{|l|}{ Liver transplant, n (\%) } \\
\hline No & 1,663 & $(94.4)$ & 1,293 & $(98.4)$ & 1,935 & $(97.0)$ & 5,653 & $(98.5)$ \\
\hline Yes & 98 & $(5.6)$ & 21 & (1.6) & 59 & $(3.0)$ & 86 & $(1.5)$ \\
\hline \multicolumn{9}{|l|}{ HIV coinfection, n (\%) } \\
\hline No & 1,734 & $(98.5)$ & 1,291 & $(98.2)$ & 1,960 & $(98.3)$ & 5,639 & $(98.3)$ \\
\hline Yes & 27 & $(1.5)$ & 23 & (1.8) & 34 & $(1.7)$ & 100 & $(1.7)$ \\
\hline \multicolumn{9}{|l|}{ CCI score, $\mathrm{n}(\%)$} \\
\hline 0 & 1,214 & $(68.9)$ & 966 & $(73.5)$ & 1,463 & $(73.4)$ & 4,769 & $(83.1)$ \\
\hline 1 & 231 & $(13.1)$ & 219 & $(16.7)$ & 263 & $(13.2)$ & 527 & $(9.2)$ \\
\hline$\geq 2$ & 316 & $(17.9)$ & 129 & $(9.8)$ & 268 & $(13.4)$ & 443 & $(7.7)$ \\
\hline \multicolumn{9}{|l|}{$\mathrm{CCI}$} \\
\hline Mean \pm SD & \multicolumn{2}{|c|}{$0.83 \pm 1.65$} & \multicolumn{2}{|c|}{$0.53 \pm 1.29$} & \multicolumn{2}{|c|}{$0.69 \pm 1.57$} & \multicolumn{2}{|c|}{$0.41 \pm 1.21$} \\
\hline Median: $\min , \max$ & \multicolumn{2}{|c|}{$0: 0,13$} & \multicolumn{2}{|c|}{$0: 0,14$} & \multicolumn{2}{|c|}{$0: 0,12$} & \multicolumn{2}{|c|}{$0: 0,13$} \\
\hline \multicolumn{9}{|c|}{ History of alcohol dependence/abuse, $\mathbf{n}(\%)$} \\
\hline No & 1,717 & $(97.5)$ & 1,292 & $(98.3)$ & 1,947 & $(97.6)$ & 5,673 & $(98.8)$ \\
\hline Yes & 44 & $(2.5)$ & 22 & $(1.7)$ & 47 & $(2.4)$ & 66 & $(1.2)$ \\
\hline \multicolumn{9}{|c|}{ History of injection/noninjection drug abuse, $\mathbf{n}(\%)$} \\
\hline No & 1,717 & $(97.5)$ & 1,249 & $(95.1)$ & 1,924 & $(96.5)$ & 5,619 & $(97.9)$ \\
\hline Yes & 44 & $(2.5)$ & 65 & $(4.9)$ & 70 & $(3.5)$ & 120 & $(2.1)$ \\
\hline
\end{tabular}

better treatment adherence, patients with a PDC value $<80 \%$ (i.e., less than $80 \%$ adherence) were classified as nonadherent. Conversely, patients with a PDC $\geq 80 \%$ were classified as being adherent to treatment. ${ }^{31}$

To determine adherence predictors, multiple logistic regression was conducted by each regimen using demographic and clinical characteristics such as sex, age group, birth date during 1945-1965, payer type, treatment option with RBV (only for $\mathrm{SOF}+\mathrm{SIM} \pm \mathrm{RBV}$ and $\mathrm{LED} / \mathrm{SOF} \pm \mathrm{RBV}$ ), health plan, liver disease severity, and CCI levels. The selected characteristics were defined a priori, and no model selection was conducted.

\section{Sustained Virologic Response}

Patients with at least $1 \mathrm{HCV}$ RNA testing result (CPT/HCPCS codes 87520, 87521, 87522, 3218F, 3220F, 3265F, G9209, and G9203) $\geq 12$ weeks following the end of the days supply of the last DAA refill were selected for SVR analysis. SVR12 was defined as an HCV RNA viral load below the limit of quantification $(25 \mathrm{IU} / \mathrm{mL})^{32}$

\section{Health Care Costs}

The 6-month drug cost following the index date was determined because the majority of patients completed the DAA treatment in accordance with FDA recommendations. Potential drugs for CHC treatment by regimens include PEG-2a, PEG-2b, RBV, LED, SIM, or SOF. Drug costs included ingredient costs, dispensing fees, and sale tax. To compare drug cost changes for CHC treatment over time, patients were grouped into 3 yearly cohorts (2013, 2014, and 2015) based on their index dates. Difference of drug costs by years were assessed by nonparametric Kruskal-Wallis tests. 
Sofosbuvir-Based Regimens for Chronic Hepatitis C in a Well-Insured U.S. Population:

Patient Characteristics, Treatment Adherence, Effectiveness, and Health Care Costs, 2013-2015

TABLE 3 Treatment Adherence and Its Predictors Among Patients Who Received SOF-Based Regimens for CHC Therapy in a U.S. Population with Commercial and Medicare Supplemental Insurance Plans, 2013-2015

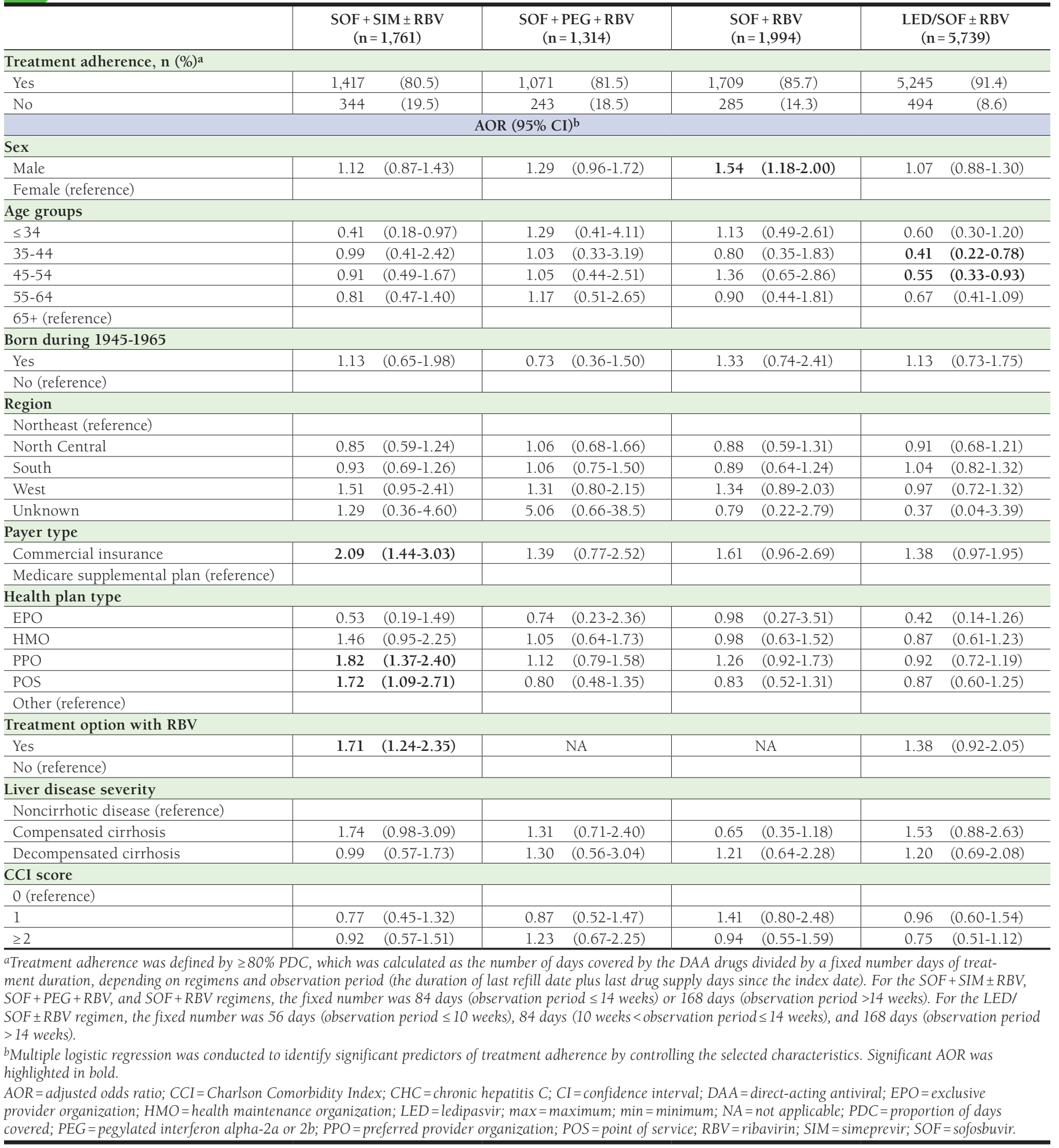




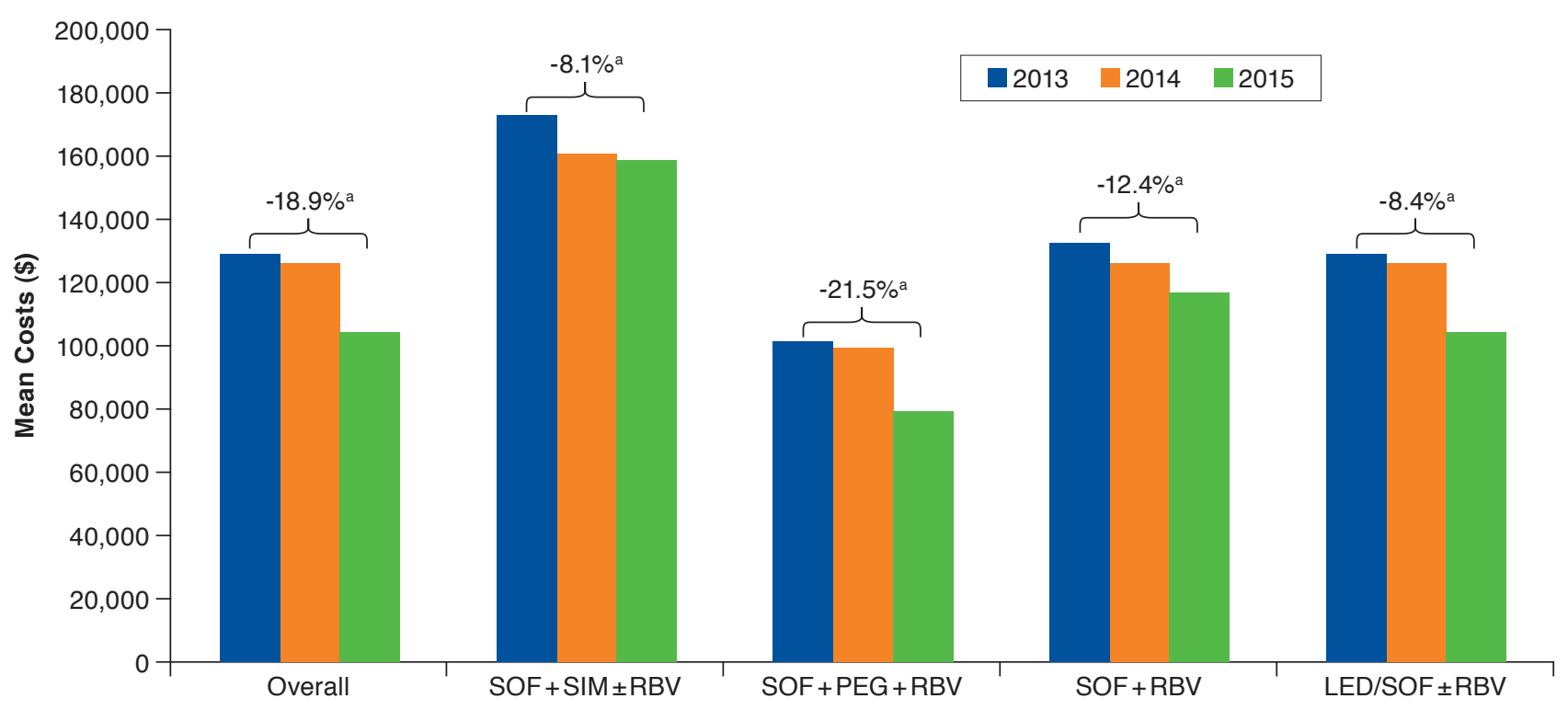

a $<<0.001$ for the nonparametric Kruskal-Wallis test.

$C H C=$ chronic hepatitis $C ; L E D=$ ledipasvir; $P E G=$ peginterferon alfa-2a or peginterferon alfa-2b; $R B V=$ ribavirin; $S I M=$ simeprevir; $S O F=s o f o s b u v i r$.

To assess medical costs changes (all-cause inpatient costs plus outpatient costs, excluding drug costs) in a relatively longterm period, patients from the study population were further selected for those who were continuously enrolled in a health plan at 1 year before and after the index dates. The 1-year total medical costs before and after the index dates were determined and compared by nonparametric Wilcoxon tests. All drug and medical cost values were measured by gross payments (including copayments, coinsurance, and deductibles) and reported in 2015 U.S. dollars after adjustment for medical cost inflation.

\section{Results}

\section{Patient Characteristics}

From the CCAE and Medicare Supplemental databases, 10,808 patients were identified who met all study inclusion criteria (Appendix A). Index dates ranged from December 2013 to July 2015, and service claims dated from December 2012 through December 2015 contributed data to the analysis. The number and percentage of patients in each of the 4 regimens were $\mathrm{SOF}+\mathrm{SIM} \pm \mathrm{RBV}(\mathrm{n}=1,761,16.3 \%) ; \mathrm{SOF}+\mathrm{PEG}+\mathrm{RBV}(\mathrm{n}=1,314$, $12.2 \%) ; \mathrm{SOF}+\mathrm{RBV}(\mathrm{n}=1,994,18.4 \%) ;$ and $\mathrm{LED} / \mathrm{SOF} \pm \mathrm{RBV}$ $(n=5,739,53.1 \%)$.

Approximately two thirds of the patients were male. The average age overall was 55 years, ranging from 53-56 years in the 4 regimens (Table 1). Patients born during 1945-1965 (i.e., "baby boomers") accounted for more than $80 \%$ of each regimen. More patients were in the South, ranging from 38\% in the $\mathrm{SOF}+\mathrm{RBV}$ regimen to $43.1 \%$ in the $\mathrm{SOF}+\mathrm{SIM} \pm \mathrm{RBV}$ regimen, compared with other geographic locations. Commercially insured patients constituted at least $79 \%$ of each regimen, with the remainder enrolled in Medicare supplemental plans. More than half of each regimen had a preferred provider organization (PPO) health plan.

Table 2 summarizes patient clinical characteristics and history of risk behaviors 1 year before the index dates by regimen. In $\mathrm{SOF}+\mathrm{SIM} \pm \mathrm{RBV}$ and $\mathrm{LED} / \mathrm{SOF} \pm \mathrm{RBV}$, the proportions of combination with RBV were $14.5 \%$ and $4.7 \%$, respectively. The percentage of patients with compensated cirrhosis ranged from $7.4 \%$ in $\mathrm{LED} / \mathrm{SOF} \pm \mathrm{RBV}$ to $13.8 \%$ in $\mathrm{SOF}+\mathrm{SIM} \pm \mathrm{RBV}$, and decompensated cirrhosis ranged from $3.9 \%$ in $\mathrm{LED} / \mathrm{SOF} \pm \mathrm{RBV}$ to $10.7 \%$ in SOF $+\mathrm{SIM} \pm \mathrm{RBV}$. Few patients had recorded diagnoses for liver cancer $(<3 \%)$, liver transplant $(<6 \%)$, or HIV coinfection $(<2 \%)$ in each regimen. Similar low levels were seen for patients with history of alcohol dependence or abuse $(<2.5 \%)$ or history of injection or noninjection drug use $(<5 \%)$. More than $80 \%$ of each regimen had a CCI score of $\leq 1.0$.

\section{Treatment Adherence}

The mean \pm standard deviation (SD) of DAA drug-covered days was $12.3 \pm 3.0$ weeks in $\mathrm{SOF}+\mathrm{SIM} \pm \mathrm{RBV} ; 12.5 \pm 5.1$ weeks in $\mathrm{SOF}+\mathrm{PEG}+\mathrm{RBV} ; 17.1 \pm 6.6$ weeks in SOF + RBV; and $13.6 \pm 6.0$ weeks in $L E D / S O F \pm R B V$, respectively. More than $80 \%$ of patients in $\mathrm{SOF}+\mathrm{SIM} \pm \mathrm{RBV}$ and $\mathrm{SOF}+\mathrm{PEG}+\mathrm{RBV}$ had drugcovered days for 12 weeks; 2 modes ( $46.9 \%$ for 12 weeks and 
Sofosbuvir-Based Regimens for Chronic Hepatitis C in a Well-Insured U.S. Population:

Patient Characteristics, Treatment Adherence, Effectiveness, and Health Care Costs, 2013-2015

TABLE 4 One-Year Medical Costs Before and After Index Dates Among Patients Who Received SOF-Based Regimens in a U.S. Population with Commercial and Medicare Supplemental Insurance Plans ${ }^{a}$

\begin{tabular}{|c|c|c|c|c|c|c|c|}
\hline \multirow{3}{*}{$\begin{array}{l}\text { One-Year Medical Costs, } \$ \text { b } \\
\text { Overall }(\mathrm{N}=4,584)\end{array}$} & \multirow{2}{*}{\multicolumn{2}{|c|}{$\begin{array}{c}\text { Before Index Date } \\
\text { Mean } \pm \text { SD (Median) }\end{array}$}} & \multirow{2}{*}{\multicolumn{2}{|c|}{$\begin{array}{c}\text { After Index Date } \\
\text { Mean } \pm \text { SD (Median) }\end{array}$}} & \multirow{2}{*}{\multicolumn{2}{|c|}{$\begin{array}{c}\text { Change (\%) } \\
\text { Mean (Median) }\end{array}$}} & \multirow{3}{*}{$\frac{\text { P Value }^{\mathrm{c}}}{<0.001}$} \\
\hline & & & & & & & \\
\hline & $4,730 \pm 22,149$ & $(1,051)$ & $4,296 \pm 20,296$ & $(881)$ & -9.2 & $(-16.2)$ & \\
\hline$\underline{\mathrm{SOF}}+\mathrm{SIM} \pm \mathrm{RBV}(\mathrm{n}=1,230)$ & $6,532 \pm 30,323$ & $(1,144)$ & $5,313 \pm 24,504$ & $(983)$ & -18.7 & $(-14.1)$ & 0.097 \\
\hline SOF+PEG + RBV $(n=825)$ & $2,427 \pm 5,730$ & $(917)$ & $3,128 \pm 9,087$ & $(847)$ & 28.9 & $(-7.6)$ & 0.216 \\
\hline SOF+RBV $(n=1,039)$ & $5,792 \pm 27,540$ & $(1,113)$ & $5,072 \pm 26,720$ & $(997)$ & -12.4 & $(-10.4)$ & 0.178 \\
\hline LED/SOF \pm RBV $(n=1,490)$ & $3,778 \pm 14,032$ & $(1,033)$ & $3,562 \pm 15,043$ & $(738)$ & -5.7 & $(-28.5)$ & $<0.001$ \\
\hline
\end{tabular}

aPatients were required to be continuously enrolled in a health plan at least 12 months before and after the index dates for the 1-year medical costs estimation. Index date was defined as the first prescription date for SIM, SOF, or LED/SOF.

${ }^{b}$ Medical costs included all inpatient costs plus outpatient costs, excluding drug costs. All cost values were reported in U.S. 2015 dollars with adjustment of medical cost inflation.

CP values for cost changes were determined by the nonparametric Wilcoxon test.

$L E D=$ ledipasvir; $P E G=$ pegylated interferon alpha-2a or pegylated interferon alpha- $2 b ; R B V=$ ribavirin; $S D=$ standard deviation; SIM =simeprevir; $S O F=s o f o s b u v i r$.

$36.1 \%$ for 24 weeks) were observed in SOF + RBV; and 3 modes (17.6\% for 8 weeks, $59.2 \%$ for 12 weeks, and $15.1 \%$ for 24 weeks) were observed in $\mathrm{LED} / \mathrm{SOF} \pm \mathrm{RBV}$. Using the $\mathrm{PDC} \geq 80 \%$ measurement, adherence rates were $80.5 \%, 81.5 \%, 85.7 \%$, and $91.4 \%$ in $\mathrm{SOF}+\mathrm{SIM} \pm \mathrm{RBV}, \mathrm{SOF}+\mathrm{PEG}+\mathrm{RBV}, \mathrm{SOF}+\mathrm{RBV}$, and $\mathrm{LED} / \mathrm{SOF} \pm \mathrm{RBV}$, respectively.

Table 3 shows adherence predictors across regimens. In $\mathrm{SOF}+\mathrm{SIM} \pm \mathrm{RBV}$, commercially insured patients had significantly higher odds of adherence than patients with Medicare supplemental plans. (adjusted odds ratio $[A O R]=2.09,95 \%$ confidence interval $[\mathrm{CI}]=1.44-3.03$ ); patients without the RBV option had significantly higher odds of adherence than those with RBV (AOR $=1.71,95 \% \mathrm{CI}=1.24-2.35)$; patients with a $\mathrm{PPO}(\mathrm{AOR}=1.82,95 \% \mathrm{CI}=1.37-2.40)$ or point-of-service $(\mathrm{AOR}=1.72,95 \% \mathrm{CI}=1.09-2.71)$ health plan were more likely to be adherent than those with the other health plans. In $\mathrm{SOF}+\mathrm{RBV}$, males were more likely be adherent than females $(\mathrm{AOR}=1.54,95 \% \mathrm{CI}=1.18-2.00)$. In $\mathrm{LED} / \mathrm{SOF} \pm \mathrm{RBV}$, patients aged 35-44 years $(\mathrm{AOR}=0.41,95 \% \mathrm{CI}=0.22-0.78)$ and $45-54$ years $(\mathrm{AOR}=0.55,95 \% \mathrm{CI}=0.39-0.93)$ had lower odds of adherence than those aged over 65 years. No significant predictor was found in SOF + PEG + RBV. Birth dates during 19451965, liver disease severity, and CCI score were not associated with adherence in any of the 4 regimens.

\section{Sustained Virologic Response}

A total of 203 patients had at least 1 valid HCV RNA testing result $\geq 12$ weeks after the end of the days supply of the last refill. The overall SVR12 was $92.6 \%$ (188/203). SVR12 rates by regimen were $100 \%$ (41/41) in SOF + SIM $\pm \mathrm{RBV}$; 83.3\% (25/30) in $\mathrm{SOF}+\mathrm{PEG}+\mathrm{RBV}$; $90.6 \%$ (29/32) in $\mathrm{SOF}+\mathrm{RBV}$; and $93 \%$ (93/100) in $\mathrm{LED} / \mathrm{SOF} \pm \mathrm{RBV}$.

\section{Health Care Costs}

The mean $\pm \mathrm{SD}$ (median) of 6-month drug costs for $\mathrm{CHC}$ treatment per patient was $\$ 160,929 \pm 35,231$ (157,361) in
$\mathrm{SOF}+\mathrm{SIM} \pm \mathrm{RBV} ; \$ 98,845 \pm 21,367(98,461)$ in SOF + PEG + RBV; $\$ 123,573 \pm 47,153(92,520)$ in SOF + RBV; and $\$ 105,568 \pm 43,937$ $(95,883)$ in $\mathrm{LED} / \mathrm{SOF} \pm \mathrm{RBV}$.

To compare the changes in drug costs for $\mathrm{CHC}$ treatment over years, patients were grouped into 3 yearly cohorts (2013, 2014, and 2015) based on their index dates (Figure 1). Overall, the mean 6-month drug costs following index dates had decreased 18.9\% $(P<0.001,2013$ vs. 2015). By regimens, the mean 6 -month drug costs had an $8.1 \%$ decrease in $\mathrm{SOF}+\mathrm{SIM} \pm \mathrm{RBV}(P<0.001,2013$ vs. 2015$) ;$ a $21.5 \%$ decrease in $\mathrm{SOF}+\mathrm{PEG}+\mathrm{RBV}(P<0.001,2013$ vs. 2015$)$; a $12.4 \%$ decrease in SOF + RBV $(P<0.001,2013$ vs. 2015); and an 8.4\% decrease in $\mathrm{LED} / \mathrm{SOF} \pm \mathrm{RBV}(P<0.001,2014$ vs. 2015-only available in 2014 and 2015 as the newest treatment option at that time). The proportion of patients using the older regimen $\mathrm{SOF}+\mathrm{SIM} \pm \mathrm{RBV}$ was $27 \%(1,691 / 6,259)$ in 2014 , with a decrease to $0.1 \%$ $(39 / 4,419)$ in 2015 . In contrast, the proportion of patients using the newer regimen $\mathrm{LED} / \mathrm{SOF} \pm \mathrm{RBV}$ increased from $28.8 \%$ $(1,806 / 6,259)$ in 2014 to $89 \%(3,933 / 4,419)$ in 2015.

Table 4 shows changes in medical costs (not including drug costs) in the 1-year period before and after the index dates. Overall, the mean \pm SD (median) of the 1-year medical costs had decreased from $\$ 4,730 \pm 22,149(1,051)$ to $\$ 4,296 \pm 20,296$ (881), with mean reduced 9.2\% $(P<0.001)$. By regimen, the mean $\pm \mathrm{SD}$ (median) of 1-year medical costs had changed from $\$ 6,532 \pm 30,323(1,144)$ to $\$ 5,313 \pm 24,504$ (983) in $\mathrm{SOF}+\mathrm{SIM} \pm \mathrm{RBV}$; from $\$ 2,427 \pm 5,730$ (917) to $\$ 3,128 \pm 9,087$ (847) in $\mathrm{SOF}+\mathrm{PEG}+\mathrm{RBV}$; from $\$ 5,792 \pm 27,540(1,113)$ to $\$ 5,072 \pm 26,720$ (997) in SOF+RBV; and from $\$ 3,778 \pm 14,032(1,033)$ to $\$ 3,562 \pm 15,043$ (738) in $\mathrm{LED} / \mathrm{SOF} \pm \mathrm{RBV}$. These changes were statistically significant in $\mathrm{LED} / \mathrm{SOF} \pm \mathrm{RBV}$ (mean reduced $5.7 \%, P<0.001$ ), but not in the other regimens.

\section{Discussion}

This study describes patient characteristics, treatment adherence, effectiveness, and health care costs in a large population 
of patients diagnosed with $\mathrm{CHC}$ and insured by commercial or Medicare supplemental plans that paid for SOF-based treatment of HCV infection. A particular strength of this analysis is the use of a large health care claims database, which captured a significant cross-section of the U.S. population (about 91 million persons). In addition, this analysis included the key transition period from the interferon-based therapy to the alloral DAA treatment of $\mathrm{CHC}$, allowing examination of therapy use and cost during the transition. Briefly, claims data show a transition from DAA therapy to the newer treatment regimens with high adherence during 2013-2015. Available data indicates high SVR rates in all of the SOF-based regimens. Although DAA drug costs were initially high, they significantly decreased over years. Medical costs also significantly decreased following the initiation of DAA treatment.

Overall, demographic characteristics were similar across patients in the SOF+SIM $\pm \mathrm{RBV}, \mathrm{SOF}+\mathrm{PEG}+\mathrm{RBV}, \mathrm{SOF}+\mathrm{RBV}$, and $\mathrm{LED} / \mathrm{SOF} \pm \mathrm{RBV}$ regimens. The majority were male, born between 1945 and 1965, and commercially insured. Proportionately more patients were located in the South, which may indicate that a large pool of patients may exist in some of the southern states or that insurance plans included in the MarketScan database disproportionately covered the South. The majority of patients in the SOF $+\mathrm{SIM} \pm \mathrm{RBV}$ and $\mathrm{LED} /$ $\mathrm{SOF} \pm \mathrm{RBV}$ regimens took the drugs without the RBV option. The severity of liver disease varied among the 4 treatment regimens, with the highest proportion of compensated or decompensated cirrhosis in $\mathrm{SOF}+\mathrm{SIM} \pm \mathrm{RBV}$ and the lowest proportions in $\mathrm{LED} / \mathrm{SOF} \pm \mathrm{RBV}$. A similar pattern was also seen with the CCI score, suggesting that patients in $\mathrm{LED} / \mathrm{SOF} \pm \mathrm{RBV}$ had less severe clinical conditions than those in SOF $+\mathrm{SIM} \pm \mathrm{RBV}$.

This study estimated that the adherence rates were $80.5 \%$, $81.5 \%, 85.7 \%$, and $91.4 \%$ for $\mathrm{SOF}+\mathrm{SIM} \pm \mathrm{RBV}, \mathrm{SOF}+\mathrm{PEG}+\mathrm{RBV}$, $\mathrm{SOF}+\mathrm{RBV}$, and $\mathrm{LED} / \mathrm{SOF} \pm \mathrm{RBV}$, respectively. Barron et al. (2016) found that over $90 \%$ completed treatment of SOF-based regimens among 249 commercially insured patients. ${ }^{32}$ Walker et al. (2015) also found that the adherence rates were $92.6 \%$ for $\mathrm{SOF}+\mathrm{SIM}$ and $89.7 \%$ for SOF $+\mathrm{SIM}+\mathrm{RBV}$ regimens. ${ }^{28}$ These number are somewhat higher than our estimates. This difference may relate to our conservative assumptions about the treatment duration. We had assumed no more than a 2-week nonadherence gap for the shorter treatment plan (e.g., 14 weeks of observation for the 12-week treatment plan). Otherwise, the longer treatment plan was assumed. This may have resulted in larger denominators for the PDC calculation and underestimated the adherence rates. In contrast to the protease inhibitor-based regimens, ${ }^{24}$ the high adherence to SOF-based regimens may be attributable to their greater tolerability.

Payer type, health plan, and treatment option with RBV were adherence predictors in $\mathrm{SOF}+\mathrm{SIM} \pm \mathrm{RBV}$, while sex and age group were adherence predictors in SOF + RBV and LED/ $\mathrm{SOF} \pm \mathrm{RBV}$, respectively. The reasons for this variability of predictors across regimens remain unknown. Baby boomers, liver disease severity, and CCI levels were not predictors of adherence in any of the 4 regimens. These results may reflect that the regimens are well tolerated, regardless of birth cohort, liver disease severity, or other comorbidities. Adherence was poorer for $\mathrm{SOF}+\mathrm{SIM}+\mathrm{RBV}$ compared with $\mathrm{SOF}+\mathrm{SIM}$. It is possible that the burden or complexity of multiple component regimens may reduce patient adherence. Consistently, Walker et al. found lower adherence rates in SOF + SIM + RBV than in $\mathrm{SOF}+\mathrm{SIM}$ using the MarketScan databases. ${ }^{28}$

This study examined the real-world effectiveness of SOFbased regimens. Because of the availability of linked claimslaboratory result data from MarketScan and the valid HCV RNA testing results, only a small subset of the patient population $(\mathrm{n}=203)$ was eligible for the analysis. The overall SVR12 was $92.6 \%$. The SVR12 rate was the highest in SOF $+\mathrm{SIM} \pm \mathrm{RBV}$ (100\%), followed by $\mathrm{LED} / \mathrm{SOF} \pm \mathrm{RBV}(93.0 \%), \mathrm{SOF}+\mathrm{RBV}$ (90.6\%), and SOF+PEG+RBV (83.3\%). These estimates were similar to those reported by other studies. ${ }^{9-18,32}$ Because of limited sample sizes, factors that associated with SVR12 rates were not assessed in this study.

The average 6-month drug cost for $\mathrm{CHC}$ treatment per patient following the initiation of DAA treatment was $\$ 160,929$ (2015 U.S. dollars) in SOF + SIM \pm RBV; $\$ 98,845$ in SOF + PEG + RBV; $\$ 123,573$ in SOF+RBV; and $\$ 105,568$ in $\mathrm{LED} / \mathrm{SOF} \pm \mathrm{RBV}$. Interestingly, the treatment with fewer components$\mathrm{SOF}+\mathrm{RBV}$ - was more expensive than SOF+PEG+RBV. One explanation is that the drug-covered days of SOF + RBV (average 17.1 weeks) was longer than that of SOF+PEG+RBV (average 12.5 weeks). Overall, these cost estimates are close to the WAC-based DAA price (e.g., LED/SOF costs $\$ 94,500$ for 12 weeks) and some potential additional costs such as dispensing fees. Consistent with our estimates, Bach and Zaiken (2016) found that the mean \pm SD (median) drug cost per patient was $\$ 130,391 \pm 46,787(113,400)$ among 322 patients with the SOF-based regimens. ${ }^{23}$ Langness et al. (2017) found that the average total costs per patient were $\$ 152,775$ for the SOF + SIM regimen. ${ }^{26}$

This study found that drug costs for CHC treatment decreased from 2013 through 2015 for all regimens, especially for the older regimens of SOF+PEG+RBV (-21.5\%) and SOF+RBV (-12.4\%). Moreover, the newer option LED/ $\mathrm{SOF} \pm \mathrm{RBV}$ accounted for the majority of patients treated with SOF-based regimens CHC in 2015. These results suggest that although DAA costs remained relatively high, costs of these drugs were declining steadily. Recent reports suggest that further reduction in drug costs continued as competing treatment options became available and large volume purchasers negotiated better prices. For example, the SOF-producer Gilead initially offered only minimal discounts to PBMs. However, after AbbVie entered the marketplace with new competing $\mathrm{CHC}$ treatment regimens, Express Scripts-one of the largest 
PBMs-was able to force deep discounts from both companies. ${ }^{33}$ More recently, and after the analysis period of our study, the FDA approved Mavyret (glecaprevir and pibrentasvir, AbbVie) to treat adults with HCV genotypes 1-6 without cirrhosis or with mild cirrhosis, ${ }^{34}$ which is by far the least expensive regimen for HCV so far, priced at $\$ 26,400$ in 2017 for an 8 -week course..$^{35}$

Finally, this study assessed the medical costs during the 1-year period before and after the index dates (the initiation of DAA treatment). Medical costs in all regimens combinedand in the $\mathrm{LED} / \mathrm{SOF} \pm \mathrm{RBV}$ regimen alone-had significantly declined 1 year after the initiation of DAA treatment. These findings may indicate the positive effects of DAA treatment on the health care system. Expanding treatment access of DAA regimens to $\mathrm{CHC}$ patients is expected to reduce the socioeconomic burdens of HCV in the long run. However, more studies are needed to analyze the cost changes of DAA treatment for longer periods.

\section{Limitations}

The findings of this study should be interpreted with the following limitations. First, this study used a large nonrandom sample from a population insured with commercial plans and with Medicare supplemental plans, which is not representative of the U.S. general population. Our results may not be applicable to other patients, such as those insured by Medicaid or Medicare fee-for-service, or uninsured populations who may have less access to hepatitis curative therapies and are in poorer health because of comorbid conditions or more advanced liver disease than was apparent in our study population. ${ }^{36}$

Second, this study assumed that a paid claim for a filled medication prescription translated into actual use of the medication, which could not be confirmed solely based on the health care claims data used in this study. However, considering the severity of the disease and good tolerability, it was very likely that patients would take the drug as recommended.

Third, HCV genotype information was not available, and data for previous treatment or cirrhosis may have been missing, all of which are necessary to characterize the likely intended treatment plan. The adherence estimates in this study are subject to bias and inaccuracy because of potential misclassification of treatment plans. We used PDC $\geq 80 \%$ to define adherence as suggested by the literature. ${ }^{31}$ However, the optimal cut-point of PDC for adherence remains to be determined. In addition, we could not distinguish the restarts of therapy due to lack of SVR results for the majority of patients.

Fourth, the percentages with a history of alcohol or drug abuse may be underestimated because patients with such problems may have little or no documentation of these risk behaviors in the claims database used in this study. ${ }^{37}$

Finally, medical and drug costs were estimated by the payment information during a fixed time. Some early or late payments in the claim process beyond that period may not have been captured, which could lead to underestimation of costs. Costs for patients aged 65 years and older may have been underestimated because only patients with a Medicare supplemental plan were included. More studies are warranted to address these limitations, possibly with other supplementary data sources, such as understanding adherence with more information such as genotype and pretreatment history, analyzing predictors of SVR rates with larger sample size, and tracking drug and medical costs during longer periods.

\section{Conclusions}

This study describes patient characteristics, treatment adherence, effectiveness, and health care costs among $\mathrm{CHC}$ patients in a large U.S. population with commercial and Medicare supplemental insurance plans who received SOF-based treatment regimens during the years 2013-2015. Results suggest that drug costs of SOF-based regimens for CHC treatment had decreased steadily, and most patients in treatment received newer regimens with lower costs with high adherence. Available data showed that SVR12 rates were close to those obtained in clinical studies. The overall medical costs (not including drug costs) had also significantly declined 1 year after the index dates. The combination of less costly regimens that have become available since 2015 and high patient adherence rates found in this study indicates encouraging opportunities for more $\mathrm{CHC}$ patients to achieve cure.

\section{Authors}

SHAOMAN YIN, PhD, MSPH; LAURIE BARKER, MSPH; JIANGLAN Z. WHITE, MD, MPH; and RUTH B. JILES, PhD, Division of Viral Hepatitis, National Center for HIVIAIDS, Viral Hepatitis, STD, and TB Prevention, Centers for Disease Control and Prevention, Atlanta, Georgia.

AUTHOR CORRESPONDENCE: Shaoman Yin, PhD, MSPH, Division of Viral Hepatitis, Centers for Disease Control and Prevention, 1600 Clifton Rd., N.E., Mailstop G37, Atlanta, GA 30333. Tel.: 404.718.5661; E-mail:wso3@cdc.gov.

\section{DISCLOSURES}

No outside funding supported this study. All authors are U.S. federal employees of the Centers for Disease Control and Prevention. The authors declare that they have no competing interests. The findings and conclusions in this research are those of the authors and do not necessarily represent the official position of the Centers for Disease Control and Prevention.

\section{ACKNOWLEDGMENTS}

The authors thank Dr. Scott D. Holmberg for his suggestions. 


\section{REFERENCES}

1. Younossi ZM, Kanwal F, Saab S, et al. The impact of hepatitis C burden: an evidence-based approach. Aliment Pharmacol Ther. 2014;39(5):518-31.

2. Palumbo E. Pegylated interferon and ribavirin treatment for hepatitis $C$ infection. Ther Adv Chronic Dis. 2011;2(1):39-45

3. Butt AA, Kanwal F. Boceprevir and telaprevir in the management of hepatitis C virus-infected patients. Clin Infec Dis. 2012;54(1):96-104.

4. Olysio (simeprevir) tablets for oral use. Janssen Therapeutics. December 3, 2013. Available at: https://www.accessdata.fda.gov/drugsatfda_docs/ label/2013/205123s001lbl.pdf. Accessed December 19, 2018.

5. Sovaldi (sofosbuvir) tablets for oral use. Gilead Sciences. Revised August 2015. Available at: https://www.accessdata.fda.gov/drugsatfda_docs/ label/2015/204671s002lbl.pdf. Accessed December 10, 2018.

6. Harvoni (ledipasvir and sofosbuvir) tablets for oral use. Gilead Sciences. Revised March 2015. Available at: https://www.accessdata.fda.gov/drugsatfda_docs/label/2015/205834s001lbl.pdf. Accessed December 10, 2018.

7. Childs-Kean LM, Hand EO. Simeprevir and sofosbuvir for treatment of chronic hepatitis C infection. Clin Ther. 2015;37(2):243-67.

8. Smith MA, Chan J, Mohammad RA. Ledipasvir-sofosbuvir: interferon-/ribavirin-free regimen for chronic hepatitis C virus infection. Ann Pharmacother. 2015;49(3):343-50

9. Jacobson IM, Gordon SC, Kowdley KV, et al. Sofosbuvir for hepatitis C genotype 2 or 3 in patients without treatment options. N Engl J Med. 2013;368(20):1867-77

10. Lawitz E, Mangia A, Wyles D, et al. Sofosbuvir for previously untreated chronic hepatitis C infection. N Engl J Med. 2013;368(20):1878-87.

11. Lawitz E, Lalezari JP, Hassanein T, et al. Sofosbuvir in combination with peginterferon alfa-2a and ribavirin for non-cirrhotic, treatment-naive patients with genotypes 1,2 , and 3 hepatitis $C$ infection: a randomised, double-blind, phase 2 trial. Lancet Infect Dis. 2013;13(5):401-08.

12. Manns M, Samuel D, Gane EJ, et al. Ledipasvir and sofosbuvir plus ribavirin in patients with genotype 1 or 4 hepatitis $C$ virus infection and advanced liver disease: a multicentre, open-label, randomised, phase 2 trial. Lancet Infect Dis. 2016;16(6):685-97.

13. Bourliere M, Bronowicki JP, de Ledinghen V, et al. Ledipasvir-sofosbuvir with or without ribavirin to treat patients with HCV genotype 1 infection and cirrhosis non-responsive to previous protease-inhibitor therapy: a randomised, double-blind, phase 2 trial (SIRIUS). Lancet Infect Dis. 2015;15(4):397-404.

14. Butt AA, Yan P, Shaikh OS, Chung RT, Sherman KE. Sofosbuvir-based regimens in clinical practice achieve SVR rates closer to clinical trials: results from ERCHIVES. Liver Inter. 2015;36(5):651-58.

15. Pillai AA, Wedd J, Norvell J, et al. Simeprevir and sofosbuvir (SMV-SOF) for 12 weeks for the treatment of chronic hepatitis $C$ genotype 1 infection: a real world (transplant) hepatology practice experience. Am J Gastroenterol. 2016;111(2):250-60.

16. Tapper EB, Bacon BR, Curry MP, et al. Real-world effectiveness for 12 weeks of ledipasvir-sofosbuvir for genotype 1 hepatitis C: the Trio Health study. J Viral Hepat. 2017;24(1):22-27.

17. Sulkowski MS, Vargas HE, Di Bisceglie AM, et al. Effectiveness of simeprevir plus sofosbuvir, with or without ribavirin, in real-world patients with HCV genotype 1 infection. Gastroenterology. 2016;150(2):419-29.

18. Welzel TM, Nelson DR, Morelli G, et al. Effectiveness and safety of sofosbuvir plus ribavirin for the treatment of HCV genotype 2 infection: results of the real-world, clinical practice HCV-TARGET study. Gut. 2017;66(10):1844-52

19. Backus LI, Belperio PS, Shahoumian TA, Loomis TP, Mole LA. Effectiveness of sofosbuvir-based regimens in genotype 1 and 2 hepatitis $C$ virus infection in 4026 U.S. veterans. Aliment Pharmacol Ther. 2015:42(5):559-73
20. Backus LI, Belperio PS, Shahoumian TA, Loomis TP, Mole LA. Realworld effectiveness of ledipasvir/sofosbuvir in 4,365 treatment-naive, genotype 1 hepatitis C-infected patients. Hepatology. 2016;64(2):405-14.

21. Backus LI, Belperio PS, Shahoumian TA, Loomis TP, Mole LA. Realworld effectiveness and predictors of sustained virological response with all-oral therapy in 21,242 hepatitis C genotype-1 patients. Antivir Ther. 2017;22(6):481-93.

22. Woolston SL, Kim HN. Cost and access to direct-acting antiviral agents. Hepatitis C Online. Retrieved May 22, 2017. Updated May 31, 2018. Available at: https://www.hepatitisc.uw.edu/go/evaluation-treatment/costaccess-medications/core-concept/all. Accessed December 19, 2018.

23. Bach TA, Zaiken K. Real-world drug costs of treating hepatitis $C$ genotypes 1-4 with direct-acting antivirals: initiating treatment at fibrosis 0-2 and 3-4. J Manag Care Spec Pharm. 2016;22(12):1437-45. Available at: https:// www.jmcp.org/doi/10.18553/jmcp.2016.22.12.1437.

24. Le TK, Kalsekar A, Macaulay D, et al. Treatment patterns, health care resource utilization, and costs in U.S. patients diagnosed with chronic hepatitis C infection who received telaprevir or boceprevir. J Manag Care Spec Pharm. 2015;21(4):308-18. Available at: https://www.jmcp.org/doi/10.18553/ jmcp.2015.21.4.308.

25. Sethi N, Tapper EB, Vong A, Sethi S, Rourke M, Afdhal NH. Direct costs of first-generation protease inhibitors for the treatment of genotype 1 chronic hepatitis C viral infection. J Viral Hepat. 2015;22(12):974-76.

26. Langness JA, Tabano D, Wieland A, et al. Curing chronic hepatitis C: a cost comparison of the combination simeprevir plus sofosbuvir vs. proteaseinhibitor-based triple therapy. Ann Hepatol. 2017;16(3):366-74.

27. Charlson ME, Pompei P, Ales KL, MacKenzie CR. A new method of classifying prognostic comorbidity in longitudinal studies: development and validation. J Chronic Dis. 1987;40(5):373-83.

28. Walker DR, Juday TR, Manthena SR, Jing Y, Sood V. The impact of ribavirin on real-world adherence rates in hepatitis $C$ patients treated with sofosbuvir plus simeprevir. Clinicoecon Outcomes Res. 2015;7:637-42.

29. Mitra D, Davis KL, Beam C, Medjedovic J, Rustgi V. Treatment patterns and adherence among patients with chronic hepatitis $C$ virus in a U.S. managed care population. Value Health. 2010;13(4):479-86.

30. Ems D, Racsa P, Anderson C, et al. Does hepatitis C treatment adherence affect risk of liver transplantation? A historical cohort study. J Manag Care Spec Pharm. 2016;22(7):863-71. Available at: https://www.jmcp.org/ doi/10.18553/jmcp.2016.22.7.863.

31. McHorney CA, Victor Spain C, Alexander CM, Simmons J. Validity of the adherence estimator in the prediction of 9-month persistence with medications prescribed for chronic diseases: a prospective analysis of data from pharmacy claims. Clin Ther. 2009;31(11):2584-607.

32. Barron J, Xie Y, Wu SJ, et al. Treatment of chronic hepatitis C infection with sofosbuvir-based regimens in a commercially insured patient population. Am Health Drug Benefits. 2016;9(6):327-35.

33. Loftus P. Special sale price: docs divided over discount on AbbVie hepatitis C drug. Wall Street Journal. December 22, 2014. Available at: https:// blogs.wsj.com/pharmalot/2014/12/22/special-sale-price-docs-divided-overdiscount-on-abbvie-hepatitis-c-drug/. Accessed December 19, 2018.

34. Mavyret (glecaprevir and pibrentasvir) tablets for oral use. AbbVie. Revised December 2017. Available at: https://www.accessdata.fda.gov/drugsatfda_docs/label/2017/209394s003lbl.pdf. Accessed December 19, 2018.

35. Sagonowsky E. AbbVie's new pan-genotypic hepatitis C drug Mavyret deeply underprices the competion. FiercePharma. August 3, 2017. Available at: https://www.fiercepharma.com/pharma/abbvie-s-new-pan-genotypichep-c-drug-mavyret-undercuts-competition. Accessed December 19, 2018

36. Canary LA, Klevens RM, Holmberg SD. Limited access to new hepatitis $C$ virus treatment under state Medicaid programs. Ann Intern Med. 2015; 163(3):226-28.

37. Boscarino JA, Moorman AC, Rupp LB, et al. Comparison of ICD-9 codes for depression and alcohol misuse to survey instruments suggests these codes should be used with caution. Dig Dis Sci. 2017;62(10):2704-12. 
Sofosbuvir-Based Regimens for Chronic Hepatitis C in a Well-Insured U.S. Population:

Patient Characteristics, Treatment Adherence, Effectiveness, and Health Care Costs, 2013-2015

\section{APPENDIX A Flowchart of Study Population and Selected Regimen Distribution}

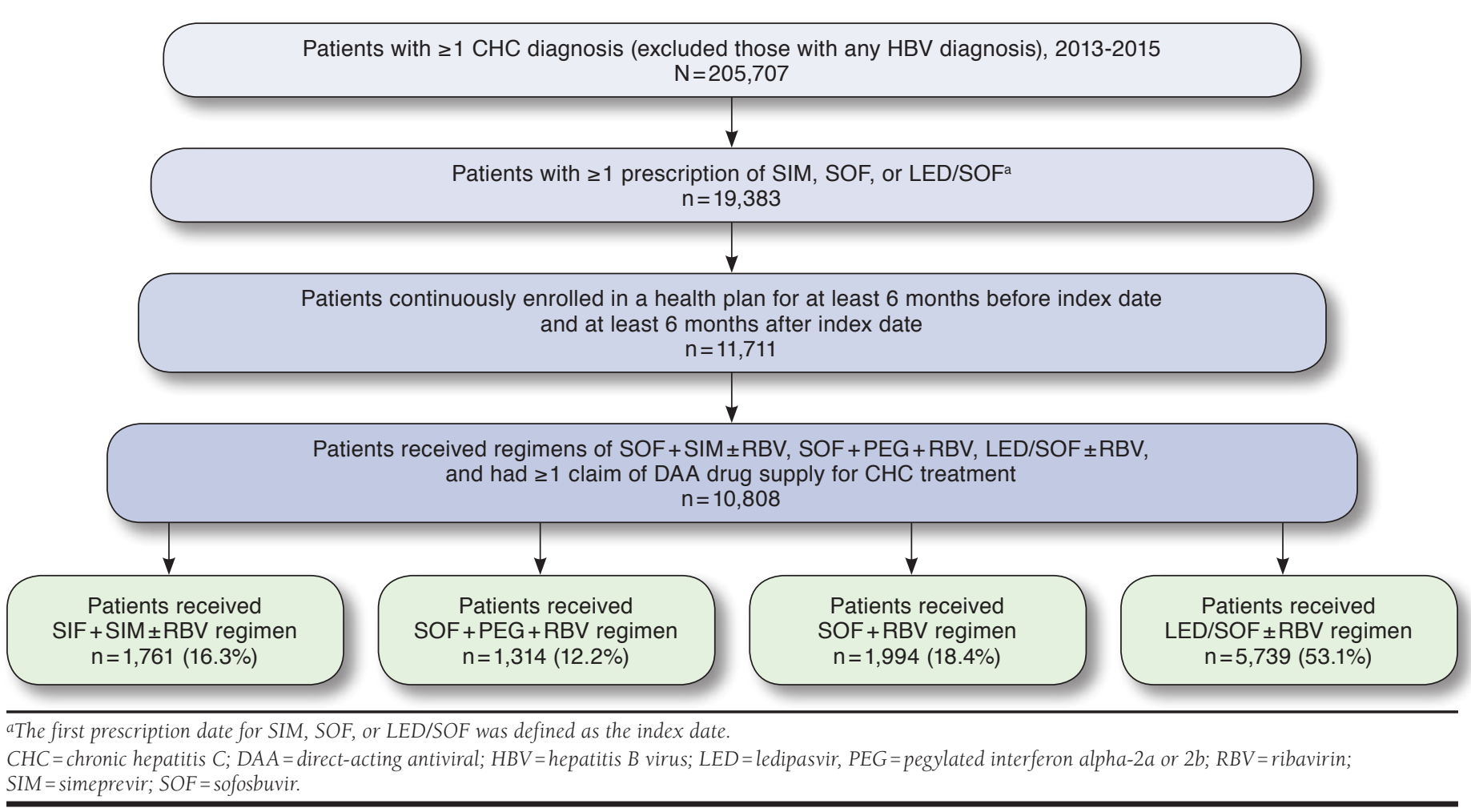


Sofosbuvir-Based Regimens for Chronic Hepatitis C in a Well-Insured U.S. Population:

Patient Characteristics, Treatment Adherence, Effectiveness, and Health Care Costs, 2013-2015

\section{APPENDIX B Diagnosis and Procedure Codes}

\begin{tabular}{|c|c|c|}
\hline Condition & Code $^{a}$ & Description \\
\hline \multirow{7}{*}{$\mathrm{HCV}$} & 070.44 & Chronic hepatitis C with hepatic coma \\
\hline & 070.54 & Chronic hepatitis C without mention of hepatic coma \\
\hline & 070.70 & Unspecified viral hepatitis C without hepatic coma \\
\hline & 070.71 & Unspecified viral hepatitis C with hepatic coma \\
\hline & B18.2 & Chronic viral hepatitis C \\
\hline & B19.20 & Unspecified viral hepatitis C without hepatic coma \\
\hline & B19.21 & Unspecified viral hepatitis $C$ with hepatic coma \\
\hline \multirow[t]{17}{*}{ HBV } & 070.20 & Viral hepatitis B with hepatic coma, acute or unspecified, without mention of hepatitis delta \\
\hline & 070.21 & Viral hepatitis B with hepatic coma, acute or unspecified, with hepatitis delta \\
\hline & 070.22 & Viral hepatitis B with hepatic coma, chronic, without mention of hepatitis delta \\
\hline & 070.23 & Viral hepatitis B with hepatic coma, chronic, with hepatitis delta \\
\hline & 070.30 & Viral hepatitis B without mention of hepatic coma, acute or unspecified, without mention of hepatitis delta \\
\hline & 070.31 & Viral hepatitis B without mention of hepatic coma, acute or unspecified, with hepatitis delta \\
\hline & 070.32 & Viral hepatitis B without mention of hepatic coma, chronic, without mention of hepatitis delta \\
\hline & 070.33 & Viral hepatitis B without mention of hepatic coma, chronic, with hepatitis delta \\
\hline & B16 & Acute hepatitis B \\
\hline & B16.0 & Acute hepatitis B with delta-agent with hepatic coma \\
\hline & B16.1 & Acute hepatitis B with delta-agent without hepatic coma \\
\hline & B16.2 & Acute hepatitis B without delta-agent with hepatic coma \\
\hline & B16.9 & Acute hepatitis B without delta-agent and without hepatic coma \\
\hline & B18.0 & Chronic viral hepatitis B with delta-agent \\
\hline & B18.1 & Chronic viral hepatitis B without delta-agent \\
\hline & B19.10 & Unspecified viral hepatitis B without hepatic coma \\
\hline & B19.11 & Unspecified viral hepatitis B with hepatic coma \\
\hline \multirow{3}{*}{$\begin{array}{l}\text { Compensated } \\
\text { cirrhosis }\end{array}$} & 571.2 & Alcoholic cirrhosis of liver \\
\hline & 571.5 & Cirrhosis of liver without mention of alcohol \\
\hline & 571.6 & Biliary cirrhosis \\
\hline \multirow{9}{*}{$\begin{array}{l}\text { Decompensated } \\
\text { cirrhosis }^{b}\end{array}$} & 070.44 & Chronic hepatitis C with hepatic coma \\
\hline & 070.71 & Unspecified viral hepatitis C with hepatic coma \\
\hline & $348.3 \mathrm{x}$ & Encephalopathy not otherwise specified \\
\hline & $\begin{array}{l}456.0,456.1, \\
456.2 \mathrm{x}\end{array}$ & Esophageal varices in diseases classified elsewhere with or without bleeding \\
\hline & 572.2 & Hepatic encephalopathy \\
\hline & 572.3 & Portal hypertension \\
\hline & 572.4 & Hepatorenal syndrome \\
\hline & 782.4 & Jaundice \\
\hline & 789.59 & Other ascites \\
\hline \multirow[t]{3}{*}{ Liver cancer } & 155 & Malignant neoplasm of liver and intrahepatic bile duct \\
\hline & 197.7 & Secondary malignant neoplasm of liver \\
\hline & 230.8 & Carcinoma in situ of liver and biliary system \\
\hline \multirow[t]{5}{*}{ Liver transplant } & V42.7 & Liver transplant \\
\hline & 47135 & Liver allotransplantation, orthotopic, partial or whole, from cadaver or living donor, any age \\
\hline & 47136 & Liver allotransplantation, heterotopic, partial or whole, from cadaver or living donor, any age \\
\hline & $50.5 \mathrm{x}$ & Liver transplant \\
\hline & 996.82 & Complications of transplanted liver \\
\hline \multirow[t]{4}{*}{ HIV/AIDS } & 042 & HIV disease \\
\hline & V08 & Asymptomatic HIV infection status \\
\hline & 795.71 & Nonspecific serologic evidence of HIV \\
\hline & 079.53 & Human immunodeficiency virus, type 2 \\
\hline
\end{tabular}


Sofosbuvir-Based Regimens for Chronic Hepatitis C in a Well-Insured U.S. Population:

Patient Characteristics, Treatment Adherence, Effectiveness, and Health Care Costs, 2013-2015

APPENDIX B Diagnosis and Procedure Codes (continued)

Condition

History of alcohol

dependence/abuse

\section{Code $^{\mathrm{a}}$}

\begin{tabular}{l|l}
305.0 & Alcohol abuse
\end{tabular}

V11.3 $\quad$ Alcoholism

\begin{tabular}{l|l}
357.5 & Alcoholic polyneuropathy
\end{tabular}

\begin{tabular}{l|l}
425.5 & Alcoholic cardiomyopathy
\end{tabular}

\begin{tabular}{l|l}
535.3 & Alcoholic gastritis \\
\hline 571.0 & Alcoholic faty liver
\end{tabular}

\begin{tabular}{l|l}
571.0 & Alcoholic fatty liver
\end{tabular}

\begin{tabular}{l|l}
571.2 & Alcoholic cirrhosis of liver
\end{tabular}

\begin{tabular}{l|l}
571.3 & Alcoholic liver damage, unspecified
\end{tabular}

\begin{tabular}{l|l} 
291.xx & Alcohol induced mental disorders
\end{tabular}

303.xx $\quad$ Alcohol dependence syndrome

Tobacco use disorder

Cannabis abuse
History of injection/ noninjection drug

abuse

$305.1 x$

$305.2 \mathrm{x}$

$305.3 \mathrm{x}$

$305.4 \mathrm{x}$

$305.5 \mathrm{x}$

$305.6 \mathrm{x}$

$305.7 \mathrm{x}$

$305.8 \mathrm{x}$

$305.9 x$

292.xx

304.xx

HCV RNA test

87520
Hallucinogen abuse

Sedative, hypnotic or anxiolytic abuse

Opioid abuse

Cocaine abuse

Amphetamine or related acting sympathomimetic abuse

Antidepressant type abuse

Other, mixed, or unspecified drug abuse

Drug induced mental disorders

Drug dependence

Infectious agent detection by nucleic acid (DNA or RNA); hepatitis C, direct probe technique

$87521 \quad$ Infectious agent detection by nucleic acid (DNA or RNA); hepatitis C, amplified probe technique, includes reverse transcription when performed

$87522 \quad$ Infectious agent detection by nucleic acid (DNA or RNA); hepatitis C, quantification, includes reverse transcription when performed

3218F $\quad$ RNA testing for hepatitis C documented as performed within 6 months prior to initiation of antiviral treatment for hepatitis C

3220F $\quad$ Hepatitis C quantitative RNA testing documented as performed at 12 weeks from initiation of antiviral treatment

3265F $\quad$ RNA testing for hepatitis $C$ viremia ordered or results documented

G9203 $\quad$ RNA testing for hepatitis C documented as performed within 12 months prior to initiation of antiviral treatment for hepatitis C

\begin{tabular}{l|l} 
G9209 & Hepatitis C quantitative RNA testing documented as performed between 4-12 weeks after the initiation of antiviral
\end{tabular} treatment

${ }^{a}$ Codes for ICD-9-CM diagnosis, ICD-10-CM diagnosis, ICD-9-CM procedure, CPT, or HCPCS procedure.

${ }^{b}$ When diagnosed in patients with $\mathrm{HCV}$, these conditions are suggestive of decompensated cirrhosis.

$C P T=$ Current Procedural Terminology; DNA; HBV=hepatitis B virus; HCPCS = Healthcare Common Procedure Coding System; HCV=hepatitis C virus;

HIV/AIDS = human immunodeficiency virus/acquired immune deficiency syndrome; ICD-9/10-CM=International Classification of Diseases, Ninth/Tenth Revision,

Clinical Modification; $R N A=$ ribonucleic acid; $S O F=$ sofosbuvir. 